\title{
Injury Estimation for Foreseen Earthquakes in an Aging Society and Its Application to Sendai City, Japan
}

\author{
Takeshi SATO* \\ Masatoshi ОвА** \\ Yotaro SHINOzAwA*** \\ Akira MANO* \\ Masato MotosaKA* \\ *Disaster Control Research Center, Tohoku University, Japan \\ **Emergency Center, Osaki Citizen Hospital, Japan \\ ***Emergency Center, Tohoku University Hospital, Japan
}

(Received April 5, 2010 Accepted August 7, 2011)

\begin{abstract}
Society is aging rapidly in Japan. For disaster mitigation against periodic earthquakes based on asperity theory in seismology, the transition of the social environment should be considered in the intervals between periodic events. This paper focuses on the aging of society as an important expansion factor in human injury. The major objective of this paper is to estimate the effects of aging on injury including serious cases caused by earthquakes. In this paper, three age classes are used as follows. Young age is defined as the generation under 14 years. Old age is defined as 65 years old or over. Middle age is defined as the other group. This classification is often used by the census.

Sendai City as the Miyagi prefectural capital is selected because it is one of the most earthquake-prone regions in Japan. The main earthquake to hit the region is the Off Miyagi earthquake with a magnitude about $7.5 \mathrm{Mj}$. This event has periodically struck Sendai City at average intervals of about 37 years.

A few assumptions are made in estimating the injury rate as a result of an Off Miyagi earthquake without a tsunami. Firstly, the normalized injury ratio proposed by the authors can be applied to estimate the injury rate for a foreseen earthquake. Secondly, the injury rate in each age class as a result of an expected Off Miyagi earthquake can be assumed to be the same as in the previous event in 1978. Finally, only the transition of the population structure regarding multiple factors can be considered in the interval between periodic events. In addition, the emergency response load of taking care of the injured elderly is proposed.

(1) In the subject region in Sendai City, the ratio of the old-age population divided by the total population has increased three and half times in the 30 years from the previous Off Miyagi Earthquake in 1978.

(2) The normalized injury ratio in the old-age class was evaluated as being two and half times that in the middle-age class.

(3) The percentage of injured in the subject region in each age class during the Off Miyagi Earthquake in 1978 was reproduced.

(4) Under the assumed occurrence of the expected Off Miyagi earthquake in 2005, the
\end{abstract}


number of injured in the subject region in each age class was estimated considering the increase in the population and the progress of the aging of society. The number of injured has increased five times in the past 30 years. The year 2005 was adopted as the assumed occurrence year of the earthquake because the fiscal year of the newest data that have already been published as population statistics of the census was 2005 at this submission.

(5) The emergency response load of taking care of the injured elderly was evaluated. The load of the middle age has increased approximately three times in the past 30 years.

Keyword: Earthquake disaster, Human injury, Aging society, Off Miyagi earthquake The injury potential due to periodic Off Miyagi earthquakes has been influenced by the aging of society. The main conclusions obtained are as follows.

\section{INTRODUCTION}

Miyagi Prefecture is one of the most earthquakeprone regions in Japan. The Earthquake Research Committee under the Japanese government evaluated the occurrence probability of earthquakes on major active faults and subduction zones in Japan. The Off Miyagi earthquake with a magnitude of $7.5 \pm 0.1 \mathrm{Mj}$ (JMA scale) is one of the major earthquake scenarios for Miyagi Prefecture. The occurrence probability within 10 years is around $70 \%$ based on the estimation on January 1st, 2009. Events with a magnitude of about 7.5 Mj have periodically struck Sendai City as the prefectural capital with a one-million population at average occurrence intervals of about 37 years. The previous event with a magnitude of $7.4 \mathrm{Mj}$ occurred on June 12th, 1978. Sendai City is selected as the subject of analysis in this paper.

For disaster mitigation against periodic earthquakes based on asperity theory in seismology, both reduction and expansion factors should be considered in the interval between periodic events. This paper focuses on aging society as an important expansion factor in human injury. The old-age population defined as being the generation older than 65 is growing rapidly in Japan, including Sendai City. The old-age group occupied $5 \%$ of the whole population of Sendai City in 1978 when the previous Off Miyagi Earthquake occurred, while it now reaches 18\%, 30 years from the previous event.

Disaster mitigation problems in an aging society were discussed by Kosaka et al. (1995) based on a survey of the actual damage situation during the Great
Hanshin Earthquake in 1995 and the individual countermeasures by elderly residents living alone in the suburbs of Tokyo. Injury prevention by older people was identified as an important problem. Lu and Miyano (1998) analyzed the transition of total deaths during major earthquake disasters in the past century in Japan for every decade in age. Vulnerability functions in human injury by earthquakes were proposed by Ohta and Ohashi (1986) as pioneers, by Shiono and Kosaka (1986), by Shiono and Krimgold (1990), by Lu and Miyano (1995), and so on. However, the effect of age on human injury is studied in a limited way. As a previous study, Kataoka (2004) performed an injury estimation during an earthquake considering the ratio of elderly persons. But concerning vulnerability to injury by age, daily life data by Naoi and Uno (1991) were substituted for the earthquake disaster. Physical seismic damage such as to building structures from a new viewpoint of considering the temporal and spatial growth of a region was estimated by Okada and Ohta (1998). They suggested the importance of long-term land use planning, especially in urban areas and the vicinities, in consideration of the time dependency of risk potential on the receiver side as well as seismic activities influencing the region.

The major objective of this paper is to estimate the effects of aging on injuries including serious cases caused by earthquakes. An outline of the estimation method is presented as follows. The contents of injury classified according to young, middle, and old age are analyzed for the latest earthquakes in Miyagi Prefecture. Data on the injured with age attributes during the 2003 Northern Miyagi Earthquake and the 2008 
Iwate-Miyagi Inland Earthquake were collected by the authors. Young age is defined as the generation under 14 years. Old age is defined as 65 years old or over. Middle age is defined as the other group. The injury rate is defined as the ratio of injured persons in every age class to the whole population. The normalized injury ratio by dividing the injury rate in every age class by the middle-age class is proposed by the authors. The number of injured in every age class during the Off Miyagi Earthquake in 1978 is estimated by applying the proposed normalized injury ratio, because the records lack detailed attributes of the injured. Two assumptions are used in the injury estimation for expected Off Miyagi earthquakes. Firstly, the injury rate of the middle-age class in the expected Off Miyagi earthquake is the same as in the previous Off Miyagi Earthquake in 1978. Secondly, the normalized injury ratio proposed by the authors can be used for any foreseen earthquake. Also, the emergency response load of taking care of injured elderly people by the middle-age group is calculated. Finally, human injury problems due to the aging of society are discussed.

\section{REGIONAL CHARACTERISTICS OF THE RESEARCH SUBJECT}

\subsection{Natural environment}

Sendai City is located almost in the center of Miyagi Prefecture and stretches from the Ou Mountain Range in the west to the Pacific Ocean in the east. The city area in Sendai has been developed upon the tableland and the river terrace lands formed by the Hirose, Natori, and Nanakita Rivers. A part of the alluvial plain in Sendai City is shown in Fig. 1 (Sendai City, 1994). In the earthquake investigation report by Sendai City (2002), strong ground motion equal to or larger than 6-lower on JMA's seismic intensity scale was estimated against the expected Off Miyagi earthquake because of the unconsolidated ground condition. Districts with high statistical seismic risk in the expected Off Miyagi earthquake obtained in the Japanese national census are very few, and they include Takasago, Shichigo, Rokugo, and so on. Rokugo is specially selected as a high-risk area in Sendai City. The Rokugo area is indicated as the area encircled by the dotted line in Fig. 1.

During the Off Miyagi Earthquake in 1978, the house damage rate as a ratio of severely damaged and collapsed houses to the total number of houses in the Rokugo region was the highest in Sendai City at approximately $1.5 \%$. Even if the number of houses in the Rokugo region comprised only $3.5 \%$ of the total in Sendai City, the number of damaged houses in the Rokugo region reached $22.7 \%$ of the total (Abe et al., 1983). The data suggest that the Rokugo region was exposed to the earthquake's strong ground motion in a natural environment.

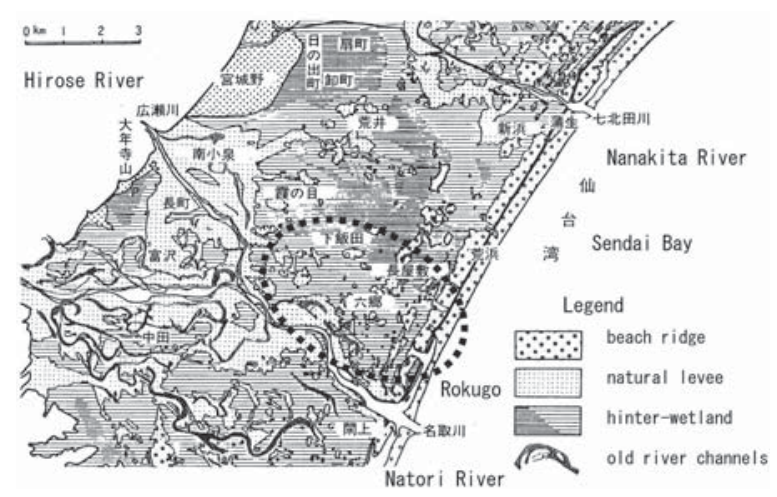

Fig. 1 Topographical classification map around the alluvial plain in Sendai City

\subsection{Change of social environment}

The Off Miyagi earthquake with a magnitude of about 7.5 Mj periodically strikes the Rokugo area at average occurrence intervals of about 37 years. There were eight small villages in the Rokugo region in the 1880s. Rokugo Village was born by the merger of eight villages in 1889. Half a century later, Rokugo Village was amalgamated with Sendai City as a neighboring big city in 1941. Some areas in Rokugo were designated as areas for urbanization in 1973. The Off Miyagi Earthquake in 1978 struck the urbanized Rokugo area.

The number of households in Rokugo over about the past 200 years is shown with the occurrence time of the periodic Off Miyagi earthquake in Fig. 2. Figure 2 suggests the situation of sudden urbanization from the 1970s. The broken lines in Fig. 2 indicate the occurrence times of the periodic Off Miyagi earthquakes. In the 200 years up to the 1960 s, the increase in the number of households was only four per year on average. The number was approximately 240 per year in the 13 years from 1965 to 1978 when the previous Off Miyagi Earthquake occurred. The rate has slowed recently, although the increase trend is continuing.

The Rokugo population by age class over about the past 50 years is shown in Fig. 3. The population 
of only the old-age group continues its increasing tendency though the other classes have already passed their peak. The number of those in the old-age class exceeded those in young-age class in 2005 and the middle-age class in 1960. Rokugo began to take on the serious character of being an aging society. Because of this situation, the extension of human injury risk is of concern.

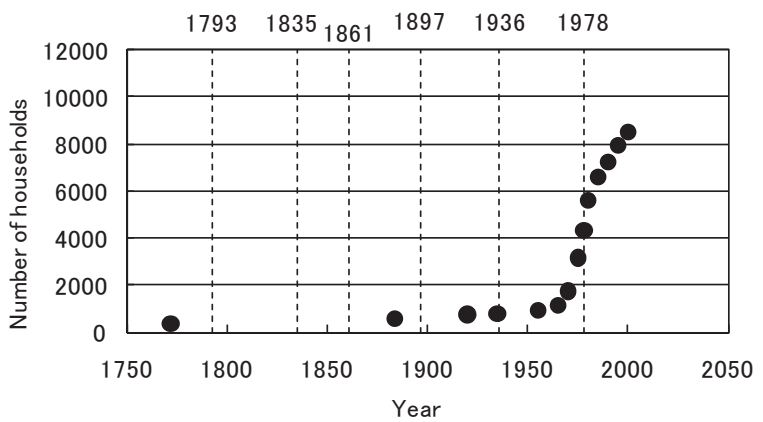

Fig. 2 Transition of the number of households and earthquake occurrence years over about the past 200 years

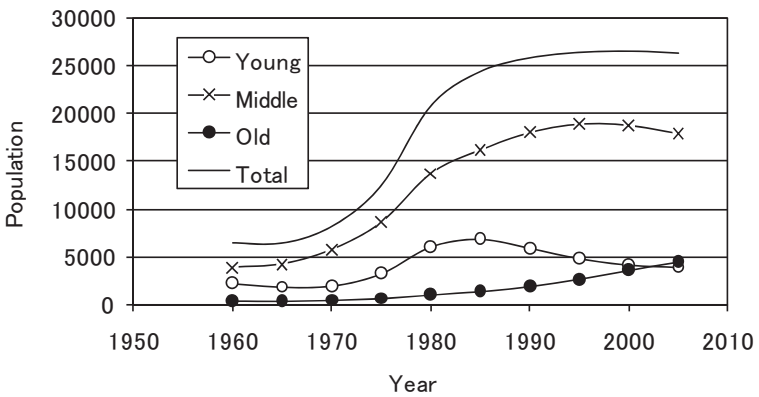

Fig. 3 Transition of the population by age class over about the past 50 years

\subsection{Change of land use}

Land use maps around the urbanized Rokugo area over about the past 70 years are shown in Fig. 4. Figure 4 (a) shows that the area was only a farming village in 1928. With an area designated for urbanization, the area was connected to the urban area in Sendai City in the 1970s. Land use after 50 years from the time point in Fig. 4 (a) is shown in Fig. 4 (b). The previous Off Miyagi Earthquake occurred just after the circumstances shown in Fig. 4 (b). Most of the Rokugo area locates the back damp on geography. The state of land use after 20 years from the event in 1978 is shown in Fig. 4 (c). It is clear that the city area was extended to the suburbs in soft-ground areas.
The reduction of physical risk such as structural damage to housing is considered, because most of the housing in the area had been built with the newest seismic design code from 1981 after the previous Off Miyagi Earthquake in 1978. But, on the other hand, because the population is exposed to strong ground motion as the natural hazard increased after 1978, the expansion of human injury risk is a cause of worry.

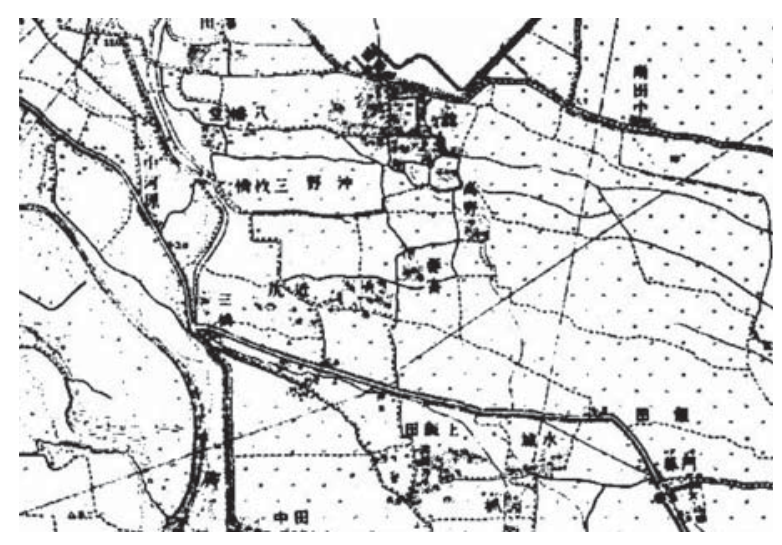

(a) 1928

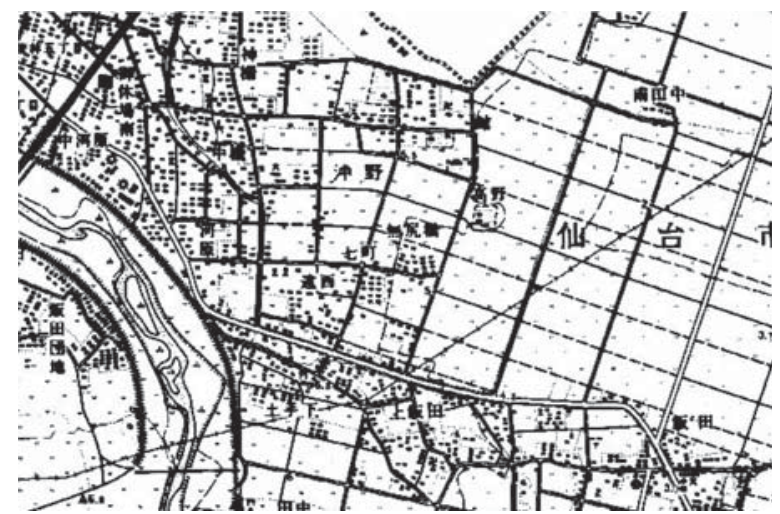

(b) 1977

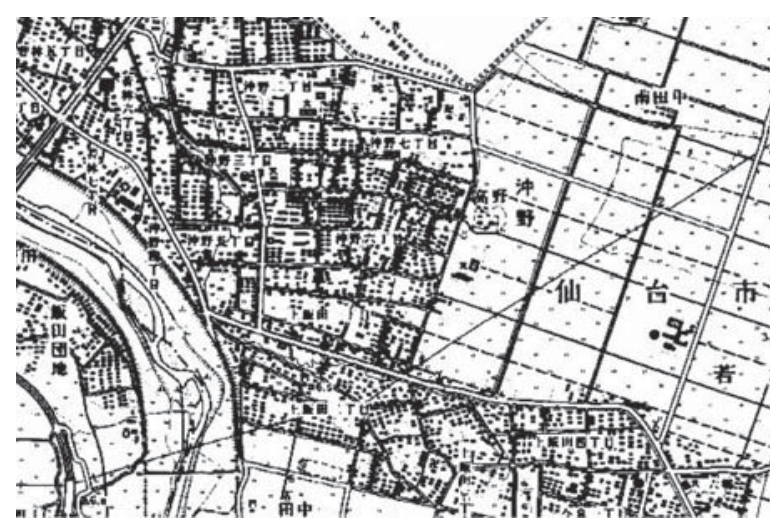

(a) 1998

Fig. 4 Land use maps around the urbanized Rokugo area over about the past 70 years (Japan Map Center, 1998) 


\section{RESULTS AND CONSIDERATION}

\subsection{Evaluation of the injury rate in a few of the latest earthquakes}

To estimate the occurrence of injury caused by the expected Off Miyagi earthquake, the change in the population structure should be reflected in the estimation. Consequentially, data not only on the total number of injured but data on injury according to age class is also necessary. Here, the data on the number of injured by age in the two latest earthquake disasters are used as an important reference. An outline of the disaster during the July 26th, 2003 Northern Miyagi Earthquake (2003 Northern Miyagi Earthquake) and the June 14th, 2008 Iwate-Miyagi Inland Earthquake (2008 Iwate-Miyagi Inland Earthquake) is shown in Tab. 1. The two are both classified as inland earthquakes. The maximum seismic intensity is also the same. There is a difference in the stricken area between plains and mountains. The major damage modes during the 2003 Northern Miyagi Earthquake were physical damage and human injury caused by the earthquake shaking structures. The 2008 IwateMiyagi Inland Earthquake caused a large-scale land slide.

Data on human injury were published by the prefectural disaster headquarters. Major data include the number of fatalities and either the slightly or the seriously injured. Effective information for reflecting the disaster lessons regarding human injury failed to be recorded. This is a common occurrence in the confusion of an earthquake disaster. Even if disaster medical scientists collect data on the injured, the focus of interest is actual emergency medical care. Useful data for the prevention of injury are not necessarily included. An investigation sheet of the injured was made based on collaboration between disaster medical science and natural disaster science to collect useful data for not only emergency medical care but also prior prevention. In spite of the delicate and private information, various valuable attributes including age were intentionally collected by the collaboration.

The injury rate according to age class based on the data of Yamoto Town by the Ishinomaki Fire Department during the 2003 Northern Miyagi Earthquake is shown as the white circle in Fig. 5 (Sato et al., 2006). The injury rate is defined as the percentage of those injured to every age group of the popula- tion, that is, the young-aged, middle-aged, and oldaged classes. The injury rate increases for the oldage group (65 years old or more) to reach $2 \%$. Similar data during the 2008 Iwate-Miyagi Inland Earthquake are shown as the black circle in Fig. 5. The data were newly collected in the Tsukidate district by the authors in cooperation with the Medical Bureau of Kurihara City. Tsukidate is a major district in Kurihara City. Both Yamoto Town and the Tsukidate district are administrative districts where the most injuries occurred in each stricken area. The injured in only the Tsukidate district amounts to just $50 \%$ of the injured in Iwate and Miyagi Prefectures during the 2008 Iwate-Miyagi Inland Earthquake. The injured in Yamoto Town reached approximately $62 \%$ of the total during the 2003 Northern Miyagi Earthquake. The data of Yamoto and Tsukidate are used as typical data during each earthquake.

An absolute quantity of the injury rate depends on the scale and the place. Therefore, the normalized injury ratio calculated by dividing the injury rate in every age class by the middle-aged class is proposed by the authors. The normalized injury ratio means vulnerability to injury caused by earthquakes according to the age class. The calculated results are shown in Fig. 6. The proposed values as round numbers are shown with dotted lines in the figure. The concrete values proposed by the authors are as follows. The normalized injury ratio in the young-age class is half that of the middle-age class. The injury ratio in the old-age class is two and a half times the level of the middle-age class. In the case of replacing the classification of every decade in age by Ohta and Ohashi (1986) during the 1978 Off Miyagi Earthquake with three age classes of young, middle, and old, a similar result to the normalized injury ratio in Fig. 6 is confirmed. Therefore, it was assumed that the proposed value could be applied to the periodic Off Miyagi earthquakes in the subduction zone, even if the result of Fig. 6 is based on inland earthquakes. 
Table 1. Outline of the latest earthquake disasters in Miyagi Prefecture

\begin{tabular}{|c|c|c|}
\hline & $\begin{array}{l}2003 \text { Northern Miyagi } \\
\text { Prefecture Earthquake }\end{array}$ & $\begin{array}{l}2008 \text { Iwate-Miyagi } \\
\text { Inland Earthquake }\end{array}$ \\
\hline Occurrence time*1 & 7:13 on 26 July, 2003 & $8: 43$ on 14 June, 2008 \\
\hline Location of epicenter & $38.40^{\circ} \mathrm{N}, 141.17^{\circ} \mathrm{E}$ & $39.03^{\circ} \mathrm{N}, 140.88^{\circ} \mathrm{E}$ \\
\hline Depth $(\mathrm{km})$ & 12 & 8 \\
\hline Magnitude*2 & 6.4 & 7.2 \\
\hline Maximum seismic intensity*2 & Upper 6 & Upper 6 \\
\hline Number of fatalities & $0 * 3$ & $14 * 4$ \\
\hline Number of those missing & $0 * 3$ & $4 * 4$ \\
\hline Number of those injured & $675 * 3$ & $365 * 4$ \\
\hline Number of collapsed houses & $1,276 * 3$ & $28 * 4$ \\
\hline Amount of damage (billion yen) & $32 * 3$ & $109 * 4$ \\
\hline
\end{tabular}

*1 Japan standard time

*2 Definition by the Japan Meteorological Agency

*3 Final release by Miyagi Prefectural Disaster Headquarters

*4 Release by Miyagi Prefectural Disaster Headquarters on September 1st, 2009

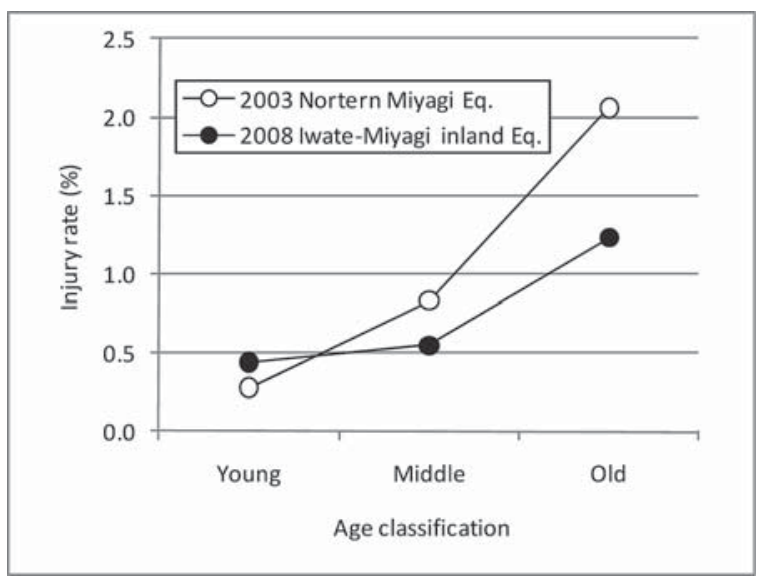

Fig. 5 Injury rate by age class

\subsection{Evaluation of the injured in Rokugo during the Off Miyagi Earthquake in 1978}

Those injured by the Off Miyagi Earthquake in 1978 in Sendai City numbered 6,256. In Rokugo, the number of those injured was 480 out of the 6,256 (Sendai City, 1979). But there are no open data regarding those injured with detailed attributes. Therefore, the number of injured according to age class during the Off Miyagi Earthquake in 1978 is estimated by applying the proposed normalized injury ratio. There is also the precondition that the injury rate of the middle-age class in expected Off Miyagi earthquakes is assumed to be same as in the Off Miyagi Earthquake in 1978. The population in Rokugo according to age class is set up to evaluate the number of injured during the Off Miyagi Earthquake in 1978.

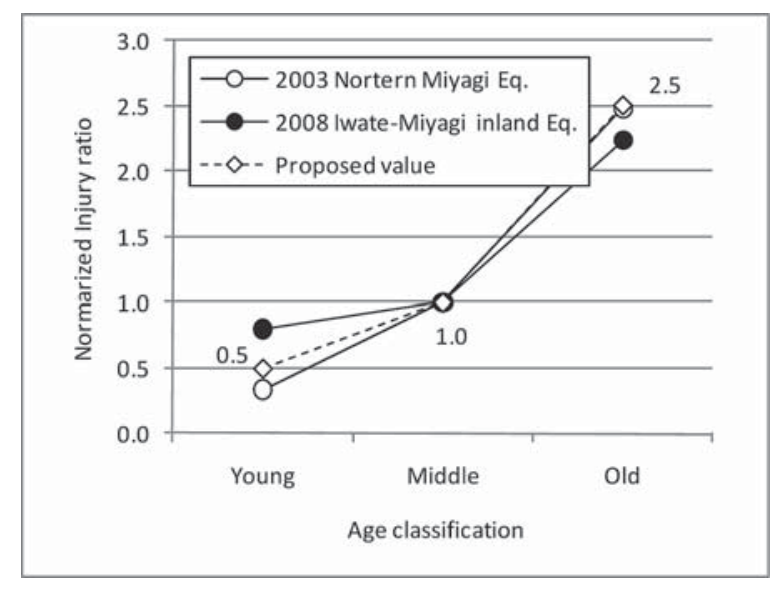

Fig. 6 Normalized injury ratio by age class

Change of the population in Rokugo according to age class in the 30 years from 1975 is shown in Tab. 2. The aging rate has changed remarkably from $5 \%$ to $17 \%$. The old-age population has increased approximately seven times in the past 30 years.

The breakdown number of the injured being 480 in 1978 is evaluated by applying the normalized injury rate of $0.5,1$, and 2.5 for the young-age class, middle-age class, and old-age class, respectively. The estimated results of the injured in Rokugo in each age class during the Off Miyagi Earthquake in 1978 are shown in Tab. 3. The number of injured in the oldage class is the same as in the young-age class in spite the population of the old-age class being one-fifth the size. The injured in the old-age class amounts to approximately $14 \%$ of the total injured. 
Table 2. Change of the population in Rokugo in the age class over 30 years

\begin{tabular}{|c|c|r|r|r|r|}
\hline \multirow{2}{*}{1} & & $\begin{array}{c}\text { Young } \\
(0 \sim 14)\end{array}$ & $\begin{array}{c}\text { Middle } \\
(15 \sim 64)\end{array}$ & $\begin{array}{c}\text { Old } \\
(65 \sim)\end{array}$ & Total \\
\hline \multirow{2}{*}{1975} & Number of population & 3,286 & 8,600 & 650 & 12,536 \\
& Percentage & 26.2 & 68.6 & 5.2 & 100.0 \\
\hline 1978 & Number of population & $4,319 *$ & $11,310 *$ & $857 *$ & 16,486 \\
\hline \multirow{2}{*}{2005} & Number of population & 3,953 & 17,904 & 4,510 & 26,367 \\
\cline { 2 - 5 } & Percentage & 15.0 & 67.9 & 17.1 & 100.0 \\
\hline
\end{tabular}

* Estimated number by applying the ratio of each class divided by the total in 1975 to the population in 1978

Table 3. Evaluation of those injured in Rokugo according to age class during the Off Miyagi Earthquake in 1978

\begin{tabular}{|c|r|r|r|r|}
\hline & \multicolumn{1}{|c|}{$\begin{array}{c}\text { Young } \\
(0 \sim 14)\end{array}$} & $\begin{array}{c}\text { Middle } \\
(15 \sim 64)\end{array}$ & $\begin{array}{c}\text { Old } \\
(65 \sim)\end{array}$ & Total \\
\hline Number of the injured (A) & 66 & 348 & 66 & 480 \\
\hline Population (B) & 4,319 & 11,310 & 857 & 16,486 \\
\hline B / A $(\times 100 \%)$ & 1.53 & 3.08 & 7.70 & 2.91 \\
\hline
\end{tabular}

\subsection{Injury estimation in Rokugo against the expected Off Miyagi earthquake}

The occurrence time of the expected Off Miyagi earthquake is assumed to be 2005. The year 2005 was adopted as the assumed occurrence year of the earthquake because the fiscal year of the newest data that were already published as population statistics of the census was 2005 at this submission. The number of those injured in Rokugo in the assumed event in 2005 is estimated considering the increase in population and the progress of the aging of society. With the above factors expected, the same condition in 1978 is applied to 2005. The injury rate in the middle-age class and the normalized injury ratio are assumed to be a numerical value that can be applied regardless of the occurrence time of the expected event. The estimated results of the injured in Rokugo according to age class are shown Tab. 4. Under the estimation, the normalized injury ratio was applied as the most important condition. The number of injured doubled in 27 years. In addition, the number in the old-age class, 338, is five times greater than in 1978, which was 66 . The great influence of the aging society is suggested regarding those injured by earthquakes.

\subsection{Evaluation of the emergency response load of caring for the injured elderly}

The emergency response load (ERL) of middleage people of caring for the injured elderly is defined as follows. The ERL is newly proposed by the authors. It means the necessary number of middle-age people to take care of injured old-age people as an emergency response by voluntary disaster prevention organizations in the neighborhood. The evaluated results are shown in Tab. 5.

\section{$\mathrm{ERL}=\mathrm{IOA} /(\mathrm{PMA}-\mathrm{IMA})$}

IOA: Number of injured in the old-age class

IMA: Number of injured in the middle-age class

PMA: Population of the middle-age class

From the results, injured elderly people could be cared for by 166 people of middle age during the Off Miyagi Earthquake in 1978. The load level has tripled in the past 30 years. The influence of the increase in the injured elderly has exceeded the effect of an increase in the middle-age population.

Table 4. Injury estimation according to age class in 2005 in Rokugo

\begin{tabular}{|c|r|r|r|r|}
\hline & \multicolumn{1}{|c|}{$\begin{array}{c}\text { Young } \\
(0 \sim 14)\end{array}$} & $\begin{array}{c}\text { Middle } \\
(15 \sim 64)\end{array}$ & $\begin{array}{c}\text { Old } \\
(65 \sim)\end{array}$ & Total \\
\hline Number of the injured (A) & 59 & 537 & 338 & 934 \\
\hline Population (B) & 3,953 & 17,904 & 4,510 & 26,367 \\
\hline B / A (×\%) & 1.49 & 3.00 & 7.49 & 3.54 \\
\hline
\end{tabular}


Table 5. Evaluation of the emergency response load of taking care of the injured elderly

\begin{tabular}{|c|c|c|c|c|}
\hline & IOA & PMA & IMA & ERL \\
\hline 1978 & 66 & 11,310 & 348 & $1 / 166$ \\
\hline 2005 & 338 & 17,904 & 537 & $1 / 51$ \\
\hline
\end{tabular}

\section{DISCUSSION}

Bold assumptions were used for injury estimation in the earthquakes, and furthermore, the variable of fatalities was excluded in this paper. But one of the problems of earthquake disaster mitigation in an aging society was analyzed quantitatively. Not only the number of the elderly injured but also the load level of middle-age people of taking care of the injured elderly has increased with the progress of aging of society. The applicable limitation of the injury rate and normalized injury ratio should be analyzed as a further extraction. In Japan, the aging of society will progress still more in the future. It is clear that the total number of injured in the old-age class should be reduced by preventive measures.

Emergency medical care workers would make efforts to reduce the number of preventable deaths. Positive efforts from the domain of natural disaster science and earthquake engineering are expected to reduce the load of emergency medical care workers. An important contribution from the domain is promoting the prevention of injury to people beforehand. When medical science researchers investigate the actual situation of disaster medicine, effective factors in the prevention of injury are not generally included. Therefore, the inclusion of multiple factors in injury estimation is necessary. The authors conducted an effective investigation during the Iwate-Miyagi Inland Earthquake by interdisciplinary collaboration between disaster medical science and natural disaster science. Effective factors not only in medical preparedness but also in prevention of injury were included in the survey specifications.

In addition, the relationship between cause and effect should be formularized to estimate with high precision which age class has been injured. The cause is exposure to shaking as a seismic hazard. The effect is risk of injury. As for the same hazard, the risk increases when vulnerability is relatively high. Vulnerability is influenced by various factors. An important factor is the age of the injured person. The place of injury and the sex of the injured person are also important factors. Therefore, human injury data should be standardized to utilize valuable disaster lessons learned from actual earthquakes with collaboration between disaster medical science and natural disaster science.

The proposed normalized injury ratio is the estimation result based on the inland earthquakes. Future tasks are the examination of the applicable limit for oceanictype earthquakes like the Off Miyagi earthquakes.

\section{CONCLUSIONS}

The injury potential due to periodic Off Miyagi earthquakes is influenced by the aging of society. In this paper, three age classes are used as follows. Young age is defined as the generation under 14 years. Old age is defined as 65 years old or over. Middle age is defined as the other group. The main conclusions obtained are as follows.

(1) In Rokugo as the subject region in Sendai City, the ratio of the old-age population divided by the total population has increased three and half times in the past 30 years from the previous Off Miyagi Earthquake in 1978.

(2) The normalized injury ratio according to age class was evaluated based on the latest earthquake disaster. The ratio in the old-age class is two and half times that in the middle-age class.

(3) The number of injured in Rokugo in each age class during the Off Miyagi Earthquake in 1978 was evaluated.

(4) Under the assumed occurrence of the expected Off Miyagi earthquake in 2005, the number of injured in Rokugo according to age class was estimated considering an increase in population and the progress of aging of society. The number of injured has increased five times in the past 30 years.

(5) The emergency load response of taking care of injured elderly people was evaluated. The load of the middle-age group has increased approxi- 
mately three times in the past 30 years.

\section{ACKNOWLEDGMENTS}

We thank the members of the Technical Working Group of the Injuries Investigation Committee during 2008 Iwate-Miyagi Inland Earthquake for helpful discussions. The committee was composed of the Liaison Conference of the Tohoku branch of the Architectural Institute of Japan, Miyagi Medical Association, the Medical Preparation Section of the Miyagi Prefectural Government, the Disaster Medical Science Section of the Miyagikenoki Earthquake Disaster Prevention Research Committee, and the Disaster Control Research Center in Tokoku University.

We are also grateful to Ishinomaki Fire Department for providing statistical data of the 2003 Northern Miyagi Earthquake used in this study. Finally, we thank the following organizations for their support in executing our investigation. The organizations are the Medical Section of the Kurihara City Government, Ohsaki Citizens' Hospital, and Furukawa Seiryo Hospital.

\section{REFERENCES}

Kosaka, S. Shiono, K., Miyano, M., Nakabayashi, I., and Takano, K., 1995. "Problem Extraction of Earthquake Disaster Prevention in an Aging Society." Papers of the Annual Conference of the Institute of Social Safety Science No. 5, 275-282 (in Japanese).

Lu, H. and Miyano, M., 1998. "Study on Age Groups and Sex Distinction in Death due to Earthquakes." AIJ Summaries of Technical Papers of Annual Meeting, 9394 (in Japanese).

Ohta, Y. and Ohashi, H., 1986. "A Semi-empirical Construction of Earthquake Casualty Equation.” Proceedings of the Seventh Japan Earthquake Engineering Symposium, 2149-2154 (in Japanese with an English abstract).

Shiono, K. and Kosaka, S., 1986. "Injuries in Earthquakes-A Study toward Assessment Schemes." Proceedings of the Seventh Japan Earthquake Engineering Symposium, 2155-2160 (in Japanese with an English abstract).

Shiono, K. and Krimgold, F., 1990. "Post-event Rapid
Estimation of Earthquake Fatalities Rescue Activity Management." Proceedings of the Eighth Japan Earthquake Engineering Symposium, 2205-2210 (in Japanese with an English abstract).

Lu, H. and Miyano, M., 1995. "Relationship between Seismic Acceleration and Casualties due to Earthquakes." Journal of Japan Society for Natural Disaster Science Vol. 14, No. 2, 161-170 (in Japanese).

Kataoka, S., 2004. "Estimation of Injuries during an Earthquake Considering the Elderly Ratio: A Case Study of the 1983 Nihon-Kai Chubu Earthquake." Tohoku Journal of Natural Disaster Science Vol. 40, 101-104 (in Japanese).

Naoi. H. and Uno. H., 1991. "On Methods for Surveys and the Quantity Grasped through Four Surveys on Japanese Dwellings-Quantity Surveys on Injuries Caused by Building-related Accidents (1)." AIJ Journal of Architecture, Planning and Environmental Engineering No. 429, 33-41 (in Japanese).

Okada, S. and Ohta, Y., 1988. "Long-term Estimation of Seismic Risk in a Temporally Expanding Urban AreaA Case Study for the Region of Sapporo, Japan.” Journal of Structural and Construction Engineering No. 389, 10-20 (in Japanese).

Sendai City, 1994. "Microtopography around the Alluvial Plain in Sendai City." History of Sendai City 88 (in Japanese).

Sendai City, 2002. "A Distribution Map of Seismic Intensity in JMA in the Expected Off Miyagi Earthquake." Investigation Report of Earthquake Damage Estimation, 2-3-27 (in Japanese).

Abe, Y. Mori, K., Tada, K. and Kimura, K., 1983. "Ratio of Wooden House Damage to All Severely Damaged including Collapsed Houses during the 1978 Off Miyagi Earthquake in Sendai City." Proceedings of the Architectural Institute of the Japan Tohoku Chapter Meeting, 197-200 (in Japanese).

Japan Map Center, 1998. Transition of Sendai Seen in Maps (in Japanese).

Sato, T. et al., 2006. "Investigation of Human Injuries during the July 26, 2003 Northern Miyagi Earthquake with Focus on Furniture Overturning." Journal of Natural Disaster Science Vol. 28, No. 1, 15-24.

Sendai City, 1979. "Outline of Human Injury.” Disaster Records during the 1978 Off Miyagi Earthquake Vol. 1, 42-43 (in Japanese). 
